\title{
Initial safety report on the tolerability of modified FOLFOX6 as adjuvant therapy in patients with curatively resected stage II or III colon cancer (JFMC41-1001-C2: JOIN trial)
}

\author{
Masahito Kotaka $^{1}$ Takayuki Yoshino ${ }^{2} \cdot \mathrm{Koji} \mathrm{Oba}^{3} \cdot \mathrm{Katsunori} \mathrm{Shinozaki}^{4} \cdot$ \\ Tetsuo Touyama ${ }^{5} \cdot$ Dai Manaka $^{6} \cdot$ Takanori Matsui $^{7} \cdot$ Kiyoshi Ishigure $^{8}$. \\ Junichi Hasegawa9 $\cdot$ Keiji Inoue $^{10}$ - Koichi Goto ${ }^{11} \cdot$ Junichi Sakamoto $^{12}$. \\ Shigetoyo Saji ${ }^{12} \cdot$ Atsushi Ohtsu $^{13} \cdot$ Toshiaki Watanabe $^{14}$
}

Received: 13 March 2015 / Accepted: 21 April 2015 / Published online: 16 May 2015

(c) The Author(s) 2015. This article is published with open access at Springerlink.com

\begin{abstract}
Purpose Adjuvant FOLFOX is a widely accepted standard therapy for resected colon cancer. The incidence of grade 3-4 peripheral sensory neuropathy (PSN) was 12.4 and $5.7 \%$ in the MOSAIC and Eastern MASCOT trials, while that of grade 3-4 allergic reactions (AR) was 2.9 and $3.1 \%$, respectively. The JFMC41-1001-C2 trial (JOIN trial) investigated the tolerability of modified FOLFOX6 (mFOLFOX6) in Japanese colon cancer patients.

Methods Twelve cycles of mFOLFOX6 were given to patients with the same eligibility criteria as in the MOSAIC study: stage II or III curatively resected colon cancer, performance status of $0-1$, aged 20 years or older, starting mFOLFOX6 within 7 weeks of surgery, and adequate organ function. The primary endpoints were the incidence of PSN persisting for $\geq 8$ days that interfered with daily activities and the incidence of grade 3-4 AR. The target sample size was 800 .
\end{abstract}

Results From November 2010 to March 2012, 882 patients were enrolled at 198 institutions. Safety was analyzed in 828 patients with finalized data out of 848 patients receiving mFOLFOX6. The incidence of PSN persisting $\geq 8$ days was $3.3 \%$ [95 \% confidence interval (CI) 2.2-4.7], while that of grade 3-4 AR was $1.7 \%$ (95\% CI 0.9-2.8). The treatment completion rate was $67.0 \%$. The median total dosage of oxaliplatin was $811.1 \mathrm{mg} / \mathrm{m}^{2}$. The overall incidence of grade 3-4 PSN was $5.8 \%$. Interstitial pneumonitis occurred in one patient. There were no treatmentrelated deaths.

Conclusions Adjuvant mFOLFOX6 is tolerable for Japanese patients with colon cancer.

Keywords Colon cancer $\cdot \mathrm{mFOLFOX6} \cdot$ Adjuvant · Peripheral sensory neuropathy $\cdot$ Allergic reactions

Takayuki Yoshino

tyoshino@east.ncc.go.jp

Gastrointestinal Cancer Center, Sano Hospital, Kobe, Japan

2 Department of Gastroenterology and Gastrointestinal Oncology, National Cancer Center Hospital East, 6-5-1 Kashiwanoha, Kashiwa, Chiba 277-8577, Japan

3 Department of Biostatistics, School of Public Health, Graduate School of Medicine and Interfaculty Initiative in Information Studies, The University of Tokyo, Tokyo, Japan

4 Division of Clinical Oncology, Hiroshima Prefectural Hospital, Hiroshima, Japan

5 Department of Surgery, Nakagami Hospital, Okinawa, Japan

6 Department of Surgery, Gastrointestinal Center, KyotoKatsura Hospital, Kyoto, Japan
7 Department of Gastroenterological Surgery, Aichi Cancer Center Aichi Hospital, Okazaki, Japan

8 Department of Surgery, Konan Kosei Hospital, Konan, Japan

9 Department of Surgery, Osaka Rosai Hospital, Sakai, Japan

10 Department of Surgery, Nagasaki Harbor Medical Center City Hospital, Nagasaki, Japan

11 Division of Thoracic Oncology, National Cancer Center Hospital East, Kashiwa, Japan

12 Japanese Foundation for Multidisciplinary Treatment of Cancer, Tokyo, Japan

13 Exploratory Oncology Research and Clinical Trial Center, National Cancer Center, Tokyo, Japan

14 Department of Surgical Oncology, The University of Tokyo, Tokyo, Japan 


\section{Introduction}

FOLFOX is the combination of 5-fluorouracil (5-FU) and $l$-leucovorin $(l$-LV) with oxaliplatin $(\mathrm{L}-\mathrm{OHP})$ and is recommended as one of the standard adjuvant chemotherapy regimens for patients with curatively resected colon cancer by the National Comprehensive Cancer Network (NCCN) guidelines [1]. In Japan, it is also recommended by the 2010 Guidelines for the Treatment of Colorectal Cancer of the Japanese Society for Cancer of the Colon and Rectum (JSCCR) [2]. Adjuvant FOLFOX is indicated for patients who have stage III colon cancer with lymph node metastasis, as well as for patients with high-risk stage II colon cancer who have risk factors for recurrence that are known to be associated with a relatively poor prognosis, such as T4 status, poorly differentiated histology, vascular invasion, ileus, $<12$ lymph nodes examined, and neural invasion [1].

The MOSAIC trial was a large-scale randomized controlled trial performed mainly in Europe that assessed the efficacy and safety of FOLFOX4 as adjuvant therapy $[3,4]$. Significant improvement in disease-free survival (DFS) and overall survival (OS) was seen in the FOLFOX4 group compared with the LV5FU2 group (receiving 1 -LV modulated infusional 5-FU therapy). In addition, the NSABP C-08 trial confirmed that modified FOLFOX6 (mFOLFOX6) therapy was equivalent to FOLFOX4 therapy in terms of efficacy and safety $[5,6]$.

Either adjuvant FOLFOX4 or mFOLFOX6 is routinely given as 12 courses ( 2 weeks per course). However, continuation of treatment is often interrupted/discontinued by the development of severe peripheral sensory neuropathy (PSN) and allergic reactions/anaphylaxis (AR). In the MOSAIC trial, the incidence of grade $\geq 1 \mathrm{PSN}$ and grade $\geq 1$ AR due to FOLFOX4 therapy was 92.0 and $10.3 \%$, respectively, while grade $\geq 3$ PSN and grade $\geq 3$ AR had an incidence of 12.4 and $2.9 \%$, respectively $[3,4]$. In the MASCOT trial, which was conducted to confirm the safety of FOLFOX4 therapy in Asian countries other than Japan (China, Hong Kong, South Korea, Taiwan, and Thailand), the incidence of grade $\geq 1$ PSN and grade $\geq 1$ AR was 86.2 and $25.2 \%$, respectively, while grade $\geq 3$ reactions showed an incidence of 5.7 and $3.1 \%$, respectively: The incidence of grade $\geq 3$ PSN and grade $\geq 1 \mathrm{AR}$ differed between the two trials [7].

In the NSABP C-08 trial, adjuvant mFOLFOX6 therapy caused grade $\geq 3$ PSN and grade $\geq 3$ AR at an incidence of 14.4 and $4.7 \%$, respectively [5], but to our knowledge, the incidence of grade $\geq 1 \mathrm{PSN}$ and grade $\geq 1$ AR has not been reported yet. In addition, there are no safety data for adjuvant mFOLFOX6 therapy in the Asian population. Therefore, we conducted the present study (JFMC411001-C2; JOIN trial) to confirm the tolerability of adjuvant mFOLFOX6 therapy in Japanese patients (UMIN ID:
000004443). Here, we report on the initial safety data from the JOIN trial.

\section{Patients and methods}

\section{Eligibility criteria}

Eligibility criteria for this study corresponded to those for the MOSAIC trial and were as follows: a pathological stage II (T3-4NOM0) or stage III (TanyN1-2M0) colon cancer [8] (including cancer of the rectosigmoid region); curative resection (curative level A) and no macroscopic and microscopic residual tumors; starting mFOLFOX6 therapy within 7 weeks after surgery and within 2 weeks after enrollment; an Eastern Cooperative Oncology Group (ECOG) performance status (PS) of $0-1$; an age of 20 years or older; no prior chemotherapy, immunotherapy, or radiation therapy; adequate function of vital organs [neutrophil count $\geq 1500$ / $\mathrm{mm}^{3}$, platelet count $\geq 100,000 / \mathrm{mm}^{3}$, serum creatinine $\leq 1.25 \times$ institutional upper limit of normal (ULN)]; total bilirubin $<2 \times \mathrm{ULN}$, aspartate aminotransferase and alanine aminotransferase $<2 \times U L N$, and carcinoembryonic antigen $<10 \mathrm{ng} / \mathrm{mL}$; no serious complications; and providing written informed consent before enrollment. The study protocol was approved in all participating institutions.

\section{Study treatment and dose modification}

The study treatment was mFOLFOX6 therapy (L-OHP, $85 \mathrm{mg} / \mathrm{m}^{2} ; 1-\mathrm{LV}, 200 \mathrm{mg} / \mathrm{m}^{2}$; 5-FU bolus, $400 \mathrm{mg} / \mathrm{m}^{2}$; and 5-FU infusion, $2400 \mathrm{mg} / \mathrm{m}^{2}$ ), with a total of 12 courses being administered at 2-week intervals. Further chemotherapy was not performed until recurrence after completion of the scheduled therapy.

If the following criteria for initiation of treatment were not met on the day of or the day before the start of each course, treatment was postponed for a maximum of 29 days: neutrophil count $\geq 1500 / \mathrm{mm}^{3}$, platelet count $\geq 75,000 / \mathrm{mm}^{3}$, and other parameters at the attending physician's discretion. If adverse events of a high enough grade occurred during the previous course, the dose was reduced by 1 level (up to 2 levels). Bolus 5-FU was discontinued after dose reduction by 1 level, but the dose of $1-\mathrm{LV}$ was not reduced. If any of the following adverse events occurred (except PSN), the doses of L-OHP and infusional 5 -FU were, respectively, reduced to 75 or $55 \mathrm{mg} / \mathrm{m}^{2}$ and 1900 or $1400 \mathrm{mg} / \mathrm{m}^{2}$ : grade $\geq 3$ (or persistent grade 2 for 2 weeks) neutropenia or thrombocytopenia and any other grade 3 non-hematological drug-related adverse events. Infusional 5-FU was reduced to 1900 or $1400 \mathrm{mg} / \mathrm{m}^{2}$ if any of the following adverse events occurred: grade 3 (or persistent grade 2 for 2 weeks) diarrhea, oral mucositis, or 


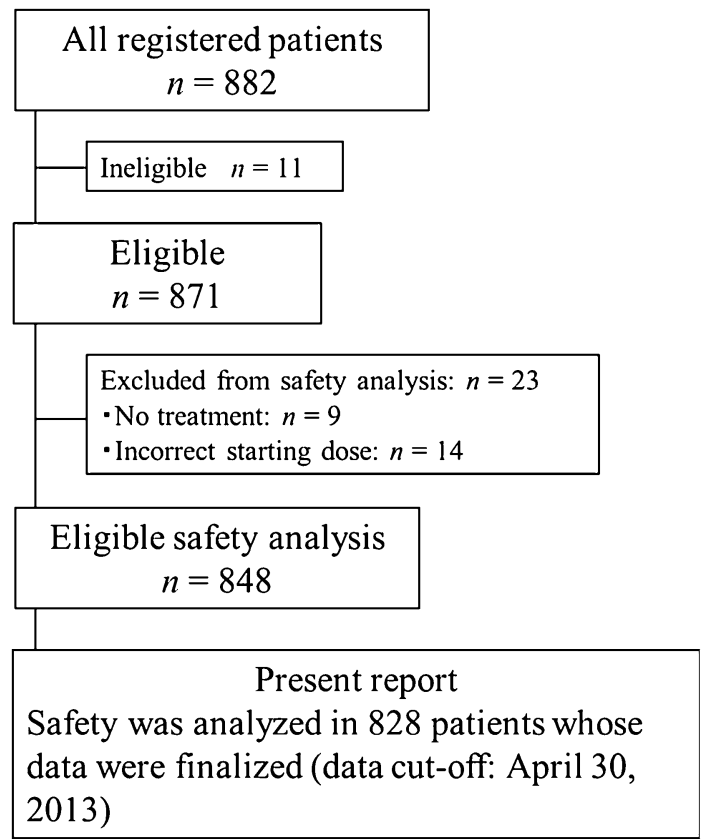

Fig. 1 CONSORT diagram

Table 1 Profile of the subjects

\begin{tabular}{ll}
\hline & 828 \\
\hline Male/female & $444 / 384$ \\
Median age (range) & $64(21-83)$ \\
Performance status 0/1 & $776 / 52$ \\
Colon/Rectosigmoid $^{\text {Stage }}{ }^{\text {II/IIIa/IIIb }}$ & $633 / 195$ \\
Stage (TNM 7th) $^{\text {b }}$ IIA/IIB/IIC/IIIA/IIIB/IIIC & $152 / 402 / 274$ \\
N0/N1/N2/N3 & $96 / 33 / 23 / 61 / 437 / 178$ \\
\hline
\end{tabular}

a General Rules for Clinical and Pathological Studies on Cancer of the Colon, Rectum, and Anus, 7th edition, revised

b TNM Classification of Malignant Tumours, 7th edition

skin disorders. Study treatment was discontinued if any of the following adverse events occurred: grade 4 diarrhea, oral mucositis, or skin disorders, and other grade 4 nonhematological drug-related adverse events. L-OHP was discontinued if grade $\geq 3$ AR occurred.

The dose of L-OHP was reduced to 75 or $55 \mathrm{mg} / \mathrm{m}^{2}$ if the patient developed persistent painless PSN for $\geq 14$ days, painful PSN for 8-13 days, or PSN with dysfunction for $\leq 7$ days. The dose of L-OHP was reduced to $55 \mathrm{mg} / \mathrm{m}^{2}$ if the patient developed persistent painful PSN for $\geq 14$ days or PSN with dysfunction for 8-13 days. L-OHP was discontinued if the patient developed persistent PSN with dysfunction for $\geq 14$ days or PSN with dysfunction for 8-13 days following painful PSN for $\geq 14$ days.

\section{Primary and secondary endpoints}

The primary endpoints were the incidence of PSN persisting for $\geq 8$ days that interfered with daily activities and the incidence of grade $\geq 3$ AR. Secondary endpoints were diseasefree survival (DFS), relapse-free survival, time to treatment failure, overall survival (OS), adverse events (AEs) including any grade of PSN or AR, comparison of PSN between patients receiving prophylactic therapy with IV calcium/ magnesium and/or oral goshajinkigan, etc., at the physician's discretion and patients not receiving such prophylactic therapy, recovery of PSN during the 3-year followup period, the treatment completion rate, the relative dose intensity (RDI), and the number of lymph node metastases, and number of dissected lymph nodes in relation to the prognosis. For prophylactic IV calcium/magnesium, goshajinkigan, and IV calcium/magnesium plus goshajinkigan, cases of concomitant use in the first course were counted.

AEs were evaluated according to the Common Terminology Criteria for Adverse Events (CTCAE) Version 4.0. However, PSN was evaluated by following the NCI-CTC Version 1.0, 2.0 and CTCAE Version 3.0. Dose intensity was calculated as the total dose divided by the duration of dosing, while the planned dose intensity was calculated as the planned dose divided by 14 . Then RDI was calculated as dose intensity/planned dose intensity $\times 100$.

\section{Enrollment and data collection}

An electronic data capture system (Viedoc ${ }^{\circledR}$, PCG Solutions, Uppsala, Sweden) was used for registration of the subjects and collection of data related to the endpoints for each patient. Central monitoring was performed, and further information was obtained from the attending physicians as required to confirm the accuracy of the data by each query. The expected enrollment period was 3 years, with an additional follow-up period of 3 years after enrollment of the last patients.

\section{Sample size and statistical analysis}

Assuming that the incidence of grade $\geq 3$ PSN is $12.0 \%$ (threshold incidence: $16.5 \%$ ) and the incidence of grade $\geq 3 \mathrm{AR}$ is $3.0 \%$ (threshold incidence: $6.5 \%$ ), based on the results of the MOSAIC trial, when the probability that a two-sided $95 \%$ confidence interval (CI) for the incidence of each adverse event does not contain the threshold incidence is set as $95 \%$, the number of patients required to evaluate grade $\geq 3$ PSN and AR was calculated to be 798 and 510 , respectively. The $95 \%$ CI was calculated by the adjusted Wald-based method [9]. Accordingly, a target of 800 patients was set for enrollment. 
Fig. 2 The incidence of PSN and $\mathrm{AR}$

Fig. 3 The cumulative incidence of PSN (grade $\geq 1 /$ grade $\geq 2 /$ grade 3 )
PSN

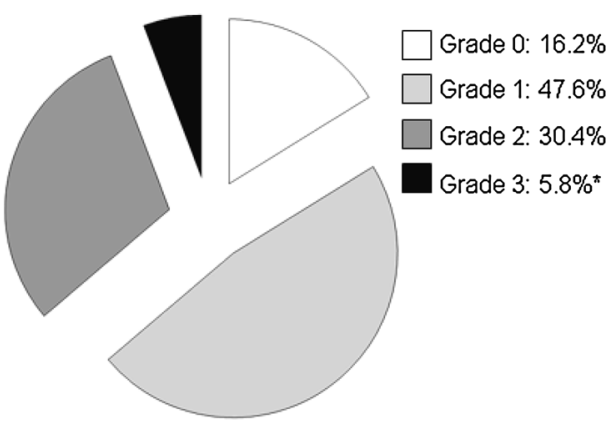

\begin{tabular}{lc}
\hline PSN & 828 \\
\hline Grade $\geq 1$ & $83.8 \%$ \\
\hline Grade 3 & $5.8 \%{ }^{*}$ \\
\hline $\begin{array}{l}\text { *Grade 3 PSN persisting for at least 8 days that } \\
\text { interfered with daily activities in } 3.3 \%\end{array}$
\end{tabular}

AR

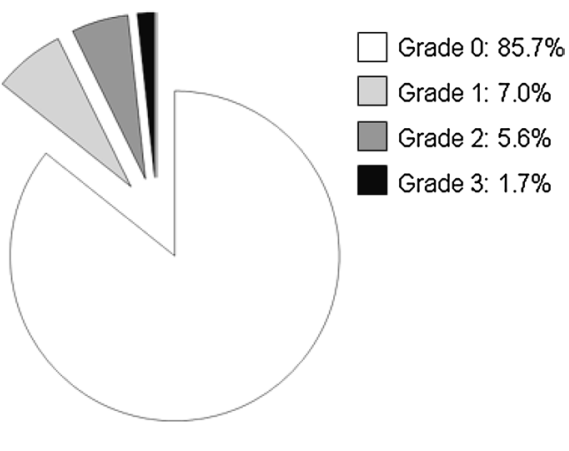

\begin{tabular}{ll} 
AR & 828 \\
\hline Grade $\geq 1$ & $14.3 \%$ \\
\hline Grade 3 & $1.7 \%$ \\
\hline
\end{tabular}

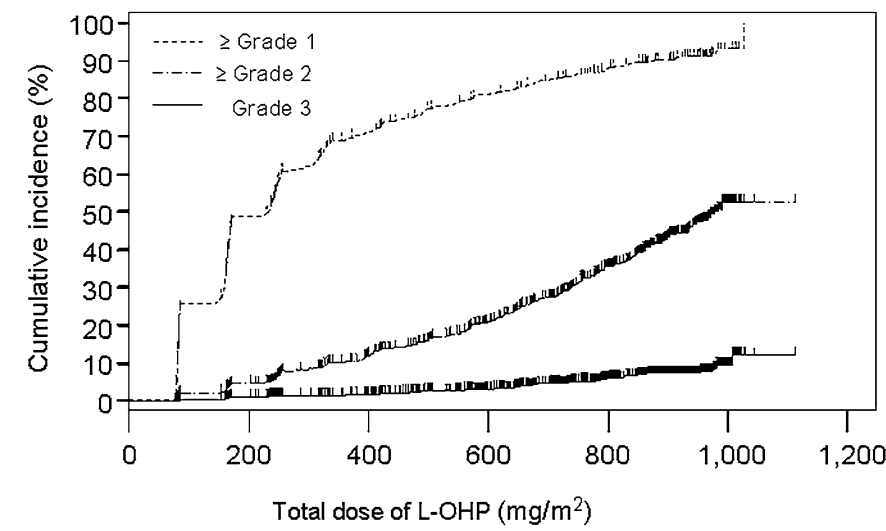

\begin{tabular}{ccccc}
\hline & \multirow{2}{*}{ Total } & \multirow{2}{*}{$n$} & \multicolumn{2}{c}{ Total dose of L-OHP $\left(\mathrm{mg}^{\mathrm{m}} \mathrm{m}^{2}\right)$} \\
\cline { 4 - 5 } & & & Median $(95 \% \mathrm{Cl})$ & Range \\
\hline Grade $\geq 1$ & 828 & 694 & $233.5(169-240.8)$ & $77.1-1,026$ \\
\hline Grade $\geq 2$ & 828 & 300 & $976.8(938.7--)$ & $77.2-1,113.6$ \\
\hline Grade 3 & 828 & 48 & $-(-)$ & $77.2-1,113.6$ \\
\hline
\end{tabular}

The incidence of grade $\geq 3 \mathrm{PSN}$ and grade $\geq 3 \mathrm{AR}$ was calculated as percentages with the adjusted Wald-based $95 \%$ CI. If the upper limit of the $95 \% \mathrm{CI}$ did not include the threshold incidence, it was concluded that adjuvant mFOLFOX6 therapy was as tolerable for Japanese patients as for Western patients. The Kaplan-Meier method was used to evaluate the relationship between the total dose and the cumulative incidence of PSN or AR. If a drug administration was stopped, data were censored at that point. The median total dose was estimated from the cumulative incidence curve, and the $95 \%$ CI was estimated by the Greenwood formula. In the pre-specified sub-analysis, the influence of prophylactic treatment and other variables on occurrence of grade $\geq 2 \mathrm{PSN}$ was evaluated in univariate and multivariate logistic regression analysis. Variables evaluated in the model were age, sex, performance status, stage, total dose of L-OHP, and prophylactic pretreatment. SAS Release 9.3 (SAS Institute, Cary, NC, USA) was used for all statistical analyses.

\section{Results}

\section{Profile of the subjects}

Between November 2010 and March 2012 (17 months), 882 patients were enrolled at 198 institutions. Among these 
Fig. 4 PSN: the incidence of each course (grade 1/grade 2/ grade 3)
Fig. 5 AR: the incidence of each course (grade 1 and 2/ grade 3 )

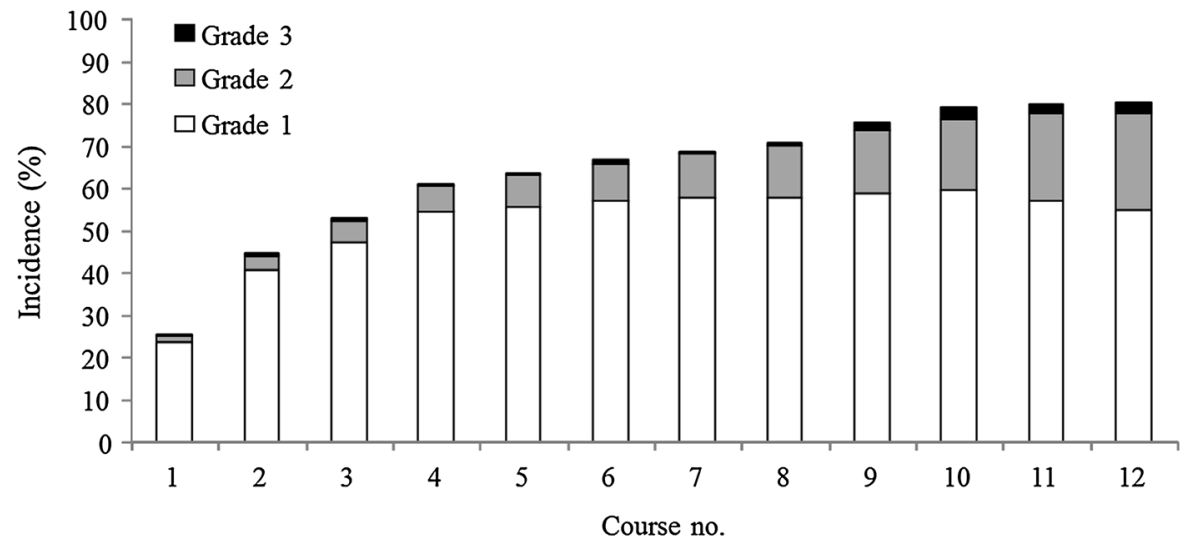

\begin{tabular}{ccccccccccccc}
\hline Course no. & 1 & 2 & 3 & 4 & 5 & 6 & 7 & 8 & 9 & 10 & 11 & 12 \\
\hline$n$ & 828 & 803 & 785 & 759 & 746 & 725 & 706 & 682 & 653 & 625 & 590 & 555 \\
\hline Grade 1 (\%) & 23.3 & 40.7 & 47.1 & 54.5 & 55.6 & 57.1 & 57.5 & 57.5 & 58.8 & 59.4 & 56.9 & 54.6 \\
\hline Grade 2 (\%) & 1.7 & 3.1 & 5.2 & 6.1 & 7.6 & 8.6 & 10.6 & 12.5 & 14.7 & 16.8 & 20.7 & 23.2 \\
\hline Grade 3 (\%) & 0.4 & 0.6 & 0.8 & 0.4 & 0.4 & 1.0 & 0.6 & 0.9 & 1.8 & 2.9 & 2.4 & 2.3 \\
\hline
\end{tabular}

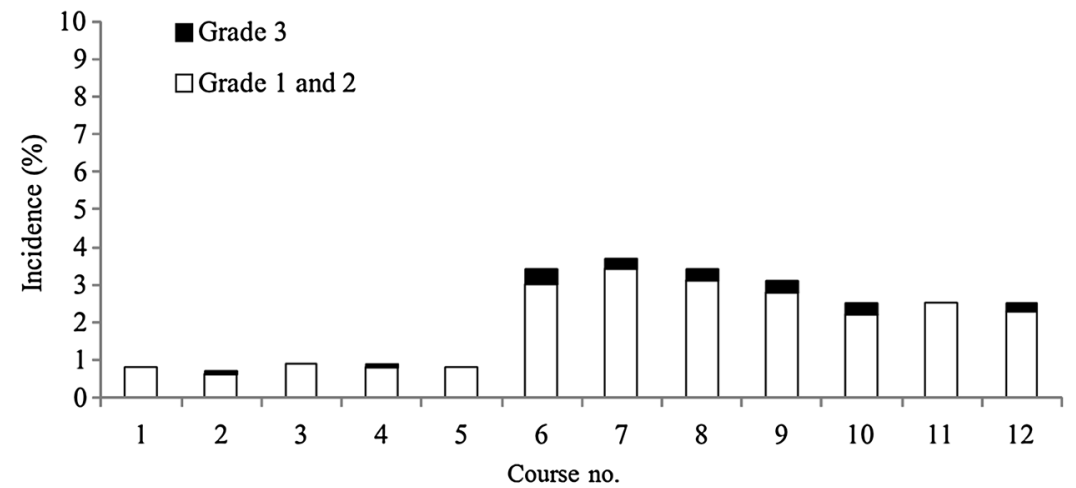

\begin{tabular}{ccccccccccccc}
\hline Course no. & 1 & 2 & 3 & 4 & 5 & 6 & 7 & 8 & 9 & 10 & 11 & 12 \\
\hline$n$ & 828 & 803 & 785 & 759 & 746 & 725 & 706 & 682 & 653 & 625 & 590 & 555 \\
\hline Grade 1 and 2 (\%) & 0.8 & 0.6 & 0.9 & 0.8 & 0.8 & 3.0 & 3.4 & 3.1 & 2.8 & 2.2 & 2.5 & 2.3 \\
\hline Grade 3 (\%) & 0.0 & 0.1 & 0.0 & 0.1 & 0.0 & 0.4 & 0.3 & 0.3 & 0.3 & 0.3 & 0.0 & 0.2 \\
\hline
\end{tabular}

882 patients, 11 were ineligible, 9 did not start the study treatment, and 14 did not receive the correct initial dosage at their physician's discretion. These 34 patients were excluded from the safety analysis by central monitoring. Of the remaining 848 patients, 828 patients for whom the treatment status was fixed by April 30, 2013, were included in the safety analysis (Fig. 1). The characteristics of these patients are shown in Table 1.

\section{Primary endpoints}

The incidence of PSN persisting for $\geq 8$ days that interfered with daily activities and the incidence of grade $\geq 3$ AR were
$3.3 \%$ (95\% CI 2.2-4.7) and $1.7 \%$ (95\% CI 1.0-2.8), respectively. At the onset of $\mathrm{PSN}$ persisting for $\geq 8$ days that interfered with daily activities, the median total dose of L-OHP and the median number of courses were $672.5 \mathrm{mg} /$ $\mathrm{m}^{2}$ and 9 , respectively, while the corresponding values were $565.1 \mathrm{mg} / \mathrm{m}^{2}$ and 7.5 at the onset of grade $\geq 3 \mathrm{AR}$.

\section{Treatment}

The median number of courses was 12 (range: $1-12$ ), and the treatment completion rate was $67.0 \%$. The median total doses of L-OHP, bolus 5-FU, and infusional 5-FU were $811.1 \mathrm{mg} / \mathrm{m}^{2}, 2798.3 \mathrm{mg} / \mathrm{m}^{2}$, and $24,009.0 \mathrm{mg} / \mathrm{m}^{2}$, 
Table 2 Relationship of variables with the onset of PSN of grade $\geq 2$ : univariate analysis

\begin{tabular}{|c|c|c|c|c|}
\hline \multirow[t]{2}{*}{ Explanatory variables } & \multicolumn{4}{|c|}{ Logistic regression analysis } \\
\hline & $n$ & $\begin{array}{l}\text { Odds ratio } \\
\text { Point estimate }\end{array}$ & $\begin{array}{l}95 \% \text { confidence } \\
\text { interval }\end{array}$ & $P$ value \\
\hline \multicolumn{5}{|l|}{ Age } \\
\hline$<70$ years old & 588 & 1.000 & - & - \\
\hline$\geq 70$ years old & 240 & 0.794 & $0.579-1.090$ & 0.1539 \\
\hline \multicolumn{5}{|l|}{ Sex } \\
\hline Male & 444 & 1.000 & - & - \\
\hline Female & 384 & 1.256 & $0.946-1.669$ & 0.1153 \\
\hline \multicolumn{5}{|l|}{ Performance status } \\
\hline 0 & 776 & 1.000 & - & - \\
\hline 1 & 52 & 1.314 & $0.743-2.321$ & 0.3477 \\
\hline \multicolumn{5}{|l|}{ Stage } \\
\hline II & 152 & 1.000 & - & - \\
\hline III & 676 & 1.114 & $0.770-1.613$ & 0.5662 \\
\hline \multicolumn{5}{|l|}{ Total dose of L-OHP } \\
\hline$<510 \mathrm{mg} / \mathrm{m}^{2}$ & 158 & 1.000 & - & - \\
\hline$\geq 510 \mathrm{mg} / \mathrm{m}^{2}$ & 670 & 2.113 & $1.417-3.151$ & $<0.001$ \\
\hline \multicolumn{5}{|l|}{ Prophylactic pretreatment } \\
\hline Without $\mathrm{Ca} / \mathrm{Mg}$ & 696 & 1.000 & - & - \\
\hline With $\mathrm{Ca} / \mathrm{Mg}$ & 132 & 1.583 & $1.087-2.307$ & 0.0168 \\
\hline Without goshajinkigan & 733 & 1.000 & - & - \\
\hline With goshajinkigan & 95 & 2.045 & $1.330-3.145$ & 0.0011 \\
\hline
\end{tabular}

For prophylactic $\mathrm{Ca} / \mathrm{Mg}$ and goshajinkigan, cases of concomitant use in the first course were counted respectively, while the median RDI was 78.2, 87.7, and $78.1 \%$, respectively.

\section{Incidence of PSN and AR}

The incidence of grade $\geq 1$ PSN was $83.8 \%$, and the incidence of grade $\geq 3$ PSN was $5.8 \%$, while the respective values for AR were 14.3 and $1.7 \%$ (Fig. 2). The cumulative incidence of each grade of PSN increased along with the total dose of L-OHP (Fig. 3). While the incidence of grade 1 PSN showed little change after the fourth course, grade 2-3 PSN tended to increase with the course number (Fig. 4). AR was observed from the first course, although its incidence particularly increased after the sixth course (Fig. 5).

\section{Pre-specified sub-analysis: effect of prophylactic treatment for PSN}

Univariate analysis of the factors related to grade $\geq 2$ PSN is shown in Table 2. In addition to a total dose of L-OHP $\geq 510 \mathrm{mg} / \mathrm{m}^{2}$, there was a significant difference in relation to the use of calcium/magnesium and use of goshajinkigan as prophylactic treatment at the initial course of mFOLFOX6, showing the likelihood of detrimental effects on grade $\geq 2$ PSN. Table 3 shows the results of the multivariate analysis of factors related to the occurrence of grade $\geq 2$ PSN, with a significant difference being observed only for a total L-OHP dose of $\geq 510 \mathrm{mg} / \mathrm{m}^{2}$. The odds ratios for prophylactic monotherapy with calcium/magnesium, monotherapy with goshajinkigan, and concomitant therapy with both agents were $1.345,1.624$, and 2.184 , respectively.

\section{Adverse events}

The AEs that occurred during this study are shown in Table 4 . The only grade $\geq 3 \mathrm{AE}$ occurring in more than $10 \%$ of the patients was neutropenia, which was observed in $28.7 \%$. However, the incidence of febrile neutropenia was $0.4 \%$. There was only one case of grade 3 interstitial pneumonitis, and there were no treatment-related deaths.

\section{Discussion}

To our knowledge, this is the first large-scale study of PSN persisting for $\geq 8$ days that interfered with daily activities and grade $\geq 3$ AR in Asian patients receiving mFOLFOX6 as adjuvant chemotherapy after curative resection of stage II or III colon cancer. The incidence of persistent PSN was $3.3 \%$ (95 \% CI 2.2-4.7), while that of grade $\geq 3$ AR was $1.7 \%$ (95\% CI 1.0-2.8). Since the upper limit of 
Table 3 Relationship of variables with the onset of $\mathrm{PSN}$ of grade $\geq 2$ : Multivariate analysis

\begin{tabular}{|c|c|c|c|c|}
\hline \multirow[t]{2}{*}{ Explanatory variables } & \multicolumn{4}{|c|}{ Logistic regression analysis } \\
\hline & $n$ & $\begin{array}{l}\text { Odds ratio } \\
\text { Point estimate }\end{array}$ & $\begin{array}{l}95 \% \text { confidence } \\
\text { interval }\end{array}$ & $P$ value \\
\hline \multicolumn{5}{|l|}{ Age } \\
\hline$<70$ years old & & 1.000 & - & - \\
\hline$\geq 70$ years old & & 0.780 & $0.562-1.083$ & 0.1377 \\
\hline \multicolumn{5}{|l|}{ Sex } \\
\hline Male & & 1.000 & - & - \\
\hline Female & & 1.266 & $0.944-1.697$ & 0.1155 \\
\hline \multicolumn{5}{|l|}{ Performance status } \\
\hline 0 & & 1.000 & - & - \\
\hline 1 & & 1.287 & $0.714-2.319$ & 0.4021 \\
\hline \multicolumn{5}{|l|}{ Stage } \\
\hline II & & 1.000 & - & - \\
\hline III & & 0.999 & $0.683-1.461$ & 0.9944 \\
\hline \multicolumn{5}{|l|}{ Total dose of L-OHP } \\
\hline$<510 \mathrm{mg} / \mathrm{m}^{2}$ & & 1.000 & - & - \\
\hline$\geq 510 \mathrm{mg} / \mathrm{m}^{2}$ & & 2.132 & $1.420-3.201$ & $<0.001$ \\
\hline \multicolumn{5}{|l|}{ Prophylactic pretreatment } \\
\hline No prior treatment & 627 & 1.000 & - & - \\
\hline $\mathrm{Ca} / \mathrm{Mg}$ (monotherapy) & 106 & 1.345 & $0.808-2.238$ & 0.2573 \\
\hline Goshajinkigan (monotherapy) & 69 & 1.624 & $0.977-2.699$ & 0.0612 \\
\hline $\begin{array}{r}\mathrm{Ca} / \mathrm{Mg}+\text { goshajinkigan } \\
\text { (concomitant therapy) }\end{array}$ & 26 & 2.184 & $0.975-4.895$ & 0.0577 \\
\hline
\end{tabular}

For prophylactic $\mathrm{Ca} / \mathrm{Mg}$, goshajinkigan, and $\mathrm{Ca} / \mathrm{Mg}$ plus goshajinkigan, cases of concomitant use in the first course were counted
Table 4 Adverse events

\begin{tabular}{lcc}
\hline & \multicolumn{1}{l}{$n(\%)$} \\
\cline { 2 - 3 } & Grade $\geq 1$ & Grade $\geq 3$ \\
\hline Neutropenia & $441(53.3 \%)$ & $238(28.7 \%)$ \\
Leucopenia & $265(32.0 \%)$ & $21(2.5 \%)$ \\
Thrombocytopenia & $264(31.9 \%)$ & $14(1.7 \%)$ \\
Diarrhea & $153(18.5 \%)$ & $17(2.1 \%)$ \\
Anorexia & $255(30.8 \%)$ & $17(2.1 \%)$ \\
Nausea & $311(37.6 \%)$ & $14(1.7 \%)$ \\
ALT (GPT) increased & $199(24.0 \%)$ & $13(1.6 \%)$ \\
Fatigue & $205(24.8 \%)$ & $10(1.2 \%)$ \\
Vomiting & $90(10.9 \%)$ & $6(0.7 \%)$ \\
AST (GOT) increased & $211(25.5 \%)$ & $5(0.6 \%)$ \\
Febrile neutropenia & $3(0.4 \%)$ & $3(0.4 \%)$ \\
Pneumonitis (interstitial pneumonitis) & $7(0.8 \%)$ & $1(0.1 \%)$ \\
\hline
\end{tabular}

CTCAE version 4.0

the $95 \%$ CI of the incidence of each event (PSN: $4.7 \%$; AR: $2.8 \%$ ) was lower than the threshold incidence (PSN: $16.5 \%$; AR: $6.5 \%$ ), the primary endpoint was met and we confirmed that both persistent PSN and grade $\geq 3$ AR were not statistically more frequent than the reported incidences in Western patients during the MOSAIC and NSABP C-08 trials.

We selected mFOLFOX6 as the regimen for this study because it is more simple and easier than FOLFOX4 in terms of administration procedure. mFOLFOX6 is widely used around the world (for example, it was the reference regimen in the NSABP C-08 study [5, 6]) because a crosssectional comparison of these two regimens for advanced and/or recurrent colorectal cancer showed comparable efficacy and safety [10].

Table 5 displays a comparison of the present findings with the results of the MOSAIC [3], MASCOT [7], and NSABP C-08 [5] trials regarding safety and administration. In the present study, the incidence of grade $\geq 3$ PSN was $5.8 \%$ (3.3\% for PSN persisting for $\geq 8$ days that interfered with daily activities), which was lower than the incidence in the MOSAIC trial (12.4\%) and the NSABP C-08 trial (14.4\%), and comparable with that in the MASCOT trial (5.7\%). The incidence of grade $\geq 3 \mathrm{AR}$ was $1.7 \%$ in this study, which was lower than in the MOSAIC (2.9\%), MASCOT (3.1\%), or NSABP C-08 (4.7\%) trials. Comparison between this study and the MOSAIC trial showed that the median course number was 12 in both, while the cumulative treatment 
Table 5 Comparison among the JOIN, MOSAIC, MASCOT, and NSABP C-08 trials

\begin{tabular}{|c|c|c|c|c|}
\hline & $\operatorname{JOIN}(n=828)$ & $\operatorname{MOSAIC}(n=1123)$ & $\operatorname{MASCOT}(n=159)$ & NSABP C-08 $(n=1350)$ \\
\hline Median number of courses & 12 & 12 & 12 & - \\
\hline Treatment completion rate (\%) & 67.0 & 74.7 & 81.8 & - \\
\hline Median total dose of L-OHP $\left(\mathrm{mg} / \mathrm{m}^{2}\right)$ & 811.1 & 810.0 & - & 850.0 \\
\hline Median RDI of L-OHP (\%) & 78.2 & 80.5 & $84.0^{\mathrm{a}}$ & 95.4 \\
\hline \multicolumn{5}{|l|}{ Adverse events (grade $\geq 3$ ) } \\
\hline Neutropenia $(\%)$ & 28.7 & $41.0^{\mathrm{c}}$ & 52.2 & $32.6^{\mathrm{d}}$ \\
\hline PSN $(\%)$ & $5.8\left(3.3^{\mathrm{b}}\right)$ & $12.4^{\mathrm{c}}$ & 5.7 & $14.4^{\mathrm{d}}$ \\
\hline $\operatorname{AR}(\%)$ & 1.7 & $2.9^{\mathrm{c}}$ & 3.1 & $4.7^{\mathrm{d}}$ \\
\hline \multicolumn{5}{|c|}{ Calculated from the dose intensity described in the report } \\
\hline \multicolumn{5}{|c|}{${ }^{\mathrm{b}}$ PSN persisting for at least 8 days that interfered with daily activities } \\
\hline \multicolumn{5}{|l|}{${ }^{c}$ Based on the data for 1.108 subjects } \\
\hline \multicolumn{5}{|l|}{${ }^{\mathrm{d}}$ Based on the data for 1321 subjects } \\
\hline
\end{tabular}

completion rate was $67.0 \%$ and $74.7 \%$, the median total dose of L-OHP was 811.1 and $810.0 \mathrm{mg} / \mathrm{m}^{2}$, and the median RDI for L-OHP was 78.2 and $80.5 \%$, respectively. In relation to tolerability, it is worth noting that the administration of therapy was similar in both studies, but the incidence of grade $\geq 3$ PSN and grade $\geq 3$ AR was lower in the present study. This was probably because it was possible to reduce the L-OHP dose by up to two levels in the present study depending on the severity and duration of PSN.

The sub-analysis did not demonstrate efficacy of prophylactic treatment for PSN. In a previous phase III clinical study [11], calcium/magnesium adjuvant therapy did not show efficacy against PSN induced by L-OHP and the present findings were consistent with that report. In a previous phase II randomized controlled study performed in patients with advanced/recurrent colorectal cancer, the Kampo medicine goshajinkigan was reported to be effective against PSN induced by FOLFOX4 therapy or mFOLFOX6 therapy [12]. However, our multivariate analysis showed that prophylactic monotherapy with calcium/magnesium, goshajinkigan, or concomitant therapy with calcium/magnesium and goshajinkigan did not prevent the development of grade $\geq 2$ PSN [hazard ratio (HR) $1.345,95 \%$ CI 0.808-2.238; HR 1.624, $95 \%$ CI 0.977-2.699; HR 2.184, $95 \%$ CI 0.975-4.895, respectively]. Similar to our study, a phase III randomized double-blind clinical study was conducted using goshajinkigan as adjuvant therapy [13]. At the interim analysis, efficacy for PSN induced by mFOLFOX6 therapy was not demonstrated and the study was terminated prematurely. In our study, prophylactic treatment with calcium/magnesium or goshajinkigan was selected at the discretion of the attending physician. Therefore, we must be cautious about potential bias as a result of non-randomized selection of patients among specific study sites and detailed explanations to patients about PSN from the investigator. Also, a relatively small number of patients on prophylactic treatment were studied, although our current results were obtained from a pre-specified sub-analysis. However, there have been no other reports about prophylactic treatment with concomitant calcium/magnesium and goshajinkigan. We found that even combining both agents did not have a preventive effect against PSN induced by L-OHP. If a prospective investigation of prophylaxis for PSN is conducted in the future, our current findings should be taken into considerations when developing the study design.

The incidence of grade $\geq 3$ neutropenia was $28.7 \%$ in this study, which was lower than in the MOSAIC (41.0\%) and MASCOT (52.2\%) trials. This was probably related to the difference in the number of bolus 5-FU doses between mFOLFOX6 therapy used in the present study and FOLFOX4 therapy used in the MOSAIC and MASCOT trials. In the NSABP C-08 study [5], mFOLFOX6 was administered as adjuvant chemotherapy to patients with curatively resected stage II or III colon cancer and the incidence of grade $\geq 3$ neutropenia was $32.6 \%$, which was comparable with that in the present study.

Among the 828 patients analyzed in this study, about $20 \%$ had stage II disease, about $60 \%$ were in stage IIIA or IIIB, and about $20 \%$ were in stage IIIC. The clinical usefulness of adjuvant chemotherapy for stage II colon cancer remains controversial because some reports have supported its efficacy [14-18] and others have not [19, 20]. Therefore, it is interesting that stage II patients accounted for approximately $20 \%$ of our subjects. This may be because exploratory analysis of 569 patients with stage II colon cancer from the MOSAIC trial [4] (282 in the FOLFOX4 group and 287 in the LV5FU2 group) who had risk factors for recurrence (one or more of T4, tumor perforation, bowel obstruction, undifferentiated tumor, vascular invasion, or $<10$ lymph nodes examined) showed that DFS at 5 years was better in the FOLFOX4 group than in the LV5FU2 group [82.1 vs. $74.9 \%$, HR 0.74 (95\% CI 0.52-1.06)]. 
The median age of the 828 patients analyzed in our study was 64 years, and 240 patients were aged 70 years or older $(29.0 \%)$. In contrast, the eligibility criteria of the MOSAIC trial included an age under 76 years, and only 315 out of 2246 patients were aged 70 years or older (14.0\%) [21]. Presumably, patients aged 70 years or older accounted for $29.0 \%$ of the present study population because an upper age limit was not set in the eligibility criteria and because the JSCCR Guidelines 2010 for the Treatment of Colorectal Cancer [2] also recommend adjuvant chemotherapy for elderly patients aged $\geq 70$ years, depending on their PS and organ function. Results for the secondary endpoints (efficacy including DFS and the longterm outcome of PSN) are not reported here and will be reported in the future.

Currently, the International Duration Evaluation of Adjuvant Chemotherapy (IDEA) collaboration is investigating whether the duration of L-OHP-based adjuvant chemotherapy can be reduced from 6 to 3 months while maintaining efficacy, and pooled analysis will be performed using data from multiple large-scale clinical studies that are ongoing around the world [22]. In Japan, the JFMC47-1202-C3 study of stage III colon cancer and the JFMC48-1301-C4 study of stage II colon cancer with risk factors for recurrence are participating in IDEA.

In conclusion, this study showed that adjuvant mFOLFOX6 therapy is tolerated in Japanese patients with curatively resected stage II or III colon cancer.

\begin{abstract}
Acknowledgments This trial was performed by the Japanese Foundation for Multidisciplinary Treatment of Cancer under contract with Yakult Honsha Co., Ltd. We thank the patients who participated in this study and their families, the physicians and medical staff of the 198 institutions registered in this study, Dr. Koichi Goto of the expert efficacy and safety evaluation committee for this study, Statcom Co. Ltd. for performing statistical analysis of the data, and the Japanese Foundation for Multidisciplinary Treatment of Cancer.
\end{abstract}

Conflict of interest J.S. received remuneration from Takeda Pharmaceutical Industry Inc. and from Tsumura Co. Ltd. The other authors declare that they have no conflict of interest.

Ethical standards All procedures performed in studies involving human participants were in accordance with the ethical standards of the institutional and/or national research committee and with the 1964 Helsinki declaration and its later amendments or comparable ethical standards.

Informed consent Informed consent was obtained from all individual participants included in the study.

Open Access This article is distributed under the terms of the Creative Commons Attribution 4.0 International License (http://creativecommons.org/licenses/by/4.0/), which permits unrestricted use, distribution, and reproduction in any medium, provided you give appropriate credit to the original author(s) and the source, provide a link to the Creative Commons license, and indicate if changes were made.

\section{References}

1. NCCN Clinical Practice Guideline: Colon Cancer. ver. 3 (2014) http://www.nccn.org/professionals/physician_gls/pdf/colon.pdf Accessed 5 December 2014

2. Watanabe T, Itabashi M, Shimada Y, Tanaka S, Ito Y, Ajioka Y, Hamaguchi T, Hyodo I, Igarashi M, Ishida H, Ishiguro M, Kanemitsu Y, Kokudo N, Muro K, Ochiai A, Oguchi M, Ohkura Y, Saito Y, Sakai Y, Ueno H, Yoshino T, Fujimori T, Koinuma N, Morita T, Nishimura G, Sakata Y, Takahashi K, Takiuchi H, Tsuruta O, Yamaguchi T, Yoshida M, Yamaguchi N, Kotake K, Sugihara K, Japanese Society for Cancer of the Colon and Rectum (2012) Japanese Society for Cancer of the Colon and Rectum (JSCCR) guidelines 2010 for the treatment of colorectal cancer. Int J Clin Oncol 17(1):1-29

3. André T, Boni C, Mounedji-Boudiaf L, Navarro M, Tabernero J, Hickish T, Topham C, Zaninelli M, Clingan P, Bridgewater J, Tabah-Fisch I, de Gramont A, Multicenter International Study of Oxaliplatin/5-Fluorouracil/Leucovorin in the Adjuvant Treatment of Colon Cancer (MOSAIC) Investigators (2004) Oxaliplatin, fluorouracil, and leucovorin as adjuvant treatment for colon cancer. N Engl J Med 350(23):2343-2351

4. André T, Boni C, Navarro M, Tabernero J, Hickish T, Topham C, Bonetti A, Clingan P, Bridgewater J, Rivera F, de Gramont A (2009) Improved overall survival with oxaliplatin, fluorouracil, and leucovorin as adjuvant treatment in stage II or III colon cancer in the MOSAIC trial. J Clin Oncol 27(19):3109-3116

5. Allegra CJ, Yothers G, O'Connell MJ, Sharif S, Colangelo LH, Lopa SH, Petrelli NJ, Goldberg RM, Atkins JN, Seay TE, Fehrenbacher L, O'Reilly S, Chu L, Azar CA, Wolmark N (2009) Initial safety report of NSABP C-08: A randomized phase III study of modified FOLFOX6 with or without bevacizumab for the adjuvant treatment of patients with stage II or III colon cancer. J Clin Oncol 27(20):3385-3390

6. Allegra CJ, Yothers G, O'Connell MJ, Sharif S, Petrelli NJ, Colangelo LH, Atkins JN, Seay TE, Fehrenbacher L, Goldberg RM, O'Reilly S, Chu L, Azar CA, Lopa S, Wolmark N (2011) Phase III trial assessing bevacizumab in stages II and III carcinoma of the colon: results of NSABP protocol C-08. J Clin Oncol 29(1):11-16

7. Po-Huang LEE, Young-Suk PARK, Jia-Fu JI, Yiu-Tung FU, Vorachai RATANATHARATHORN (2009) Safety and tolerability of FOLFOX4 in the adjuvant treatment of colon cancer in Asian patients: the MASCOT study. Asia-Pacific J Clin Oncol 5(2): $101-110$

8. Sobin LH, Gospodarowicz MK, Wittekind Ch (eds) (2009) International Union Against Cancer (UICC) TNM classification of malignant tumours, 7th edn. Wiley, Oxford

9. Agresti A, Coull B (1998) Approximate is better than 'exact' for interval estimation of binomial proportions. Am Stat 52:119-126

10. Nagata N, Kondo K, Kato T, Shibata Y, Okuyama Y, Ikenaga M, Tanemura H, Oba K, Nakao A, Sakamoto J, Mishima H (2009) Multicenter phase II study of FOLFOX for metastatic colorectal cancer (mCRC) in Japan; SWIFT-1 and 2 study. Hepatogastroenterology 56(94-95):1346-1353

11. Loprinzi CL, Qin R, Dakhil SR, Fehrenbacher L, Flynn KA, Atherton P, Seisler D, Qamar R, Lewis GC, Grothey A (2014) Phase III randomized, placebo-controlled, double-blind study of intravenous calcium and magnesium to prevent oxaliplatininduced sensory neurotoxicity (N08CB/Alliance). J Clin Oncol 32(10):997-1005

12. Kono T, Hata T, Morita S, Munemoto Y, Matsui T, Kojima H, Takemoto H, Fukunaga M, Nagata N, Shimada M, Sakamoto J, Mishima H (2013) Goshajinkigan oxaliplatin neurotoxicity evaluation (GONE): a phase 2, multicenter, randomized, 
double-blind, placebo-controlled trial of goshajinkigan to prevent oxaliplatin-induced neuropathy. Cancer Chemother Pharmacol 72(6): 1283-1290

13. Oki E, Emi Y, Kojima H, Higashijima J, Kato T, Miyake Y, Kon M, Ogata Y, Takahashi K, Ishida H, Saeki H, Sakaguchi Y, Yamanaka T, Kono T, Tomita N, Baba H, Shirabe K, Kakeji Y, Maehara Y (2015) Preventive effect of Goshajinkigan on peripheral neurotoxicity of FOLFOX therapy (GENIUS trial): a placebo-controlled, double-blind, randomized phase III study. Int J Clin Oncol. Jan 28 (Epub ahead of print)

14. Quasar Collaborative Group (2007) Adjuvant chemotherapy versus observation in patients with colorectal cancer: a randomised study. Lancet 370:2020-2029

15. Mamounas E, Wieand S, Wolmark N, Bear HD, Atkins JN, Song K, Jones J, Rockette H (1999) Comparative efficacy of adjuvant chemotherapy in patients with Dukes' B versus Dukes' C colon cancer: results from four National Surgical Adjuvant Breast and Bowel Project adjuvant studies (C-01, C-02, C-03, and C-04). J Clin Oncol 17(5):1349-1355

16. Gill S, Loprinzi CL, Sargent DJ, Thomé SD, Alberts SR, Haller DG, Benedetti J, Francini G, Shepherd LE, Francois Seitz J, Labianca R, Chen W, Cha SS, Heldebrant MP, Goldberg RM (2004) Pooled analysis of fluorouracil-based adjuvant therapy for stage II and III colon cancer: who benefits and by how much? J Clin Oncol 22(10):1797-1806

17. Sargent D, Sobrero A, Grothey A, O’Connell MJ, Buyse M, Andre T, Zheng Y, Green E, Labianca R, O'Callaghan C, Seitz JF, Francini G, Haller D, Yothers G, Goldberg R, de Gramont A (2009) Evidence for cure by adjuvant therapy in colon cancer: observations based on individual patient data from 20,898 patients on 18 randomized trials. J Clin Oncol 27(6):872-877

18. McKenzie S, Nelson R, Mailey B, Lee W, Chung V, Shibata S, Garcia-Aguilar J, Kim J (2011) Adjuvant chemotherapy improves survival in patients with American Joint Committee on Cancer stage II colon cancer. Cancer 117(24):5493-5499

19. Moertel CG, Fleming TR, Macdonald JS, Haller DG, Laurie JA, Tangen CM, Ungerleider JS, Emerson WA, Tormey DC, Glick JH (1995) Intergroup study of fluorouracil plus levamisole as adjuvant therapy for stage II/Dukes' B2 colon cancer. J Clin Oncol 13(12):2936-2943

20. Marsoni S (1999) International multicenter pooled analysis of colon, cancer trials: investigators. Efficacy of adjuvant fluorouracil and folinic acid in B2 colon cancer. International Multicentre Pooled Analysis of B2 Colon Cancer Trials (IMPACT B2) Investigators. J Clin Oncol 17(5):1356-1363

21. Tournigand C, André T, Bonnetain F, Chibaudel B, Lledo G, Hickish T, Tabernero J, Boni C, Bachet JB, Teixeira L, de Gramont A (2012) Adjuvant therapy with fluorouracil and oxaliplatin in stage II and elderly patients (between ages 70 and 75 years) with colon cancer: subgroup analyses of the Multicenter International Study of Oxaliplatin, Fluorouracil, and Leucovorin in the Adjuvant Treatment of Colon Cancer trial. J Clin Oncol 30(27):3353-3360

22. André T, Iveson T, Labianca R, Meyerhardt JA, Souglakos I, Yoshino T, Paul J, Sobrero A, Taieb J, Shields AF, Ohtsu A, Grothey A, Sargent DJ, for the IDEA Steering Committee (2013) The IDEA (International Duration Evaluation of Adjuvant Chemotherapy) collaboration: prospective combined analysis of phase III trials investigating duration of adjuvant therapy with the FOLFOX (FOLFOX4 or modified FOLFOX6) or XELOX (3 versus 6 months) regimen for patients with stage III colon cancer: trial design and current status. Curr Colorectal Cancer Rep 9:261-269 